\title{
Infecções do trato urinário (ITU) de cães e gatos: etiologia e resistência aos antimicrobianos ${ }^{1}$
}

\author{
Vania M. Carvalho' ${ }^{2}$, Tatiana Spinola ${ }^{2}$, Fabrizia Tavolari² ${ }^{2}$ Kinue Irino ${ }^{3}$, Rosana M. \\ Oliveira ${ }^{4}$ e Maria Christina C. Ramos ${ }^{4}$
}

\begin{abstract}
Carvalho V.M., Spinola T., Tavolari F., Irino K., Oliveira R.M. \& Ramos M.C.C. 2014. [Urinary tract infection (UTI) in dogs and cats: etiology and antimicrobial resistance.] Infecção do trato urinário (ITU) de cães e gatos: etiologia e resistência aos antimicrobianos. Pesquisa Veterinária Brasileira 34(1):62-70. Laboratório de Biologia Molecular e Celular, Universidade Paulista, Av. José Maria Whitaker 290, 3o andar, São Paulo, SP 04057-000, Brazil.E-mail: vaniamc@uol.com.br

Bacterial urinary tract infections (UTIs) are a common cause of disease in dogs, cats and humans. Although Gram-positive bacteria such as Staphylococcus spp., Streptococcus spp. and Enterococcus spp. are linked with UTIs, Gram-negative bacteria (Escherichia coli, Proteus spp., Klebsiella spp., Pseudomonas spp. and Enterobacter spp.) account for $75 \%$ of the cases. This study aimed to determine the frequency of different genera of bacteria in UTIs of dogs and cats as well as their susceptibility to antimicrobials used in clinical routine. Therefore, urine samples from 100 dogs and cats suspected of UTI were collected aseptically. Samples underwent to microbiological evaluation through qualitative and quantitative methods, and urinalysis. All isolates were tested for antimicrobial susceptibility. UTI was confirmed in $74 \%$ of animals, with no predominance in one gender. With regard to age, $85 \%$ of dogs and $87 \%$ of cats were older than six years. Ninety-five bacterial strains were isolated with higher frequency of Escherichia coli (55\% of total) of serogroups 06 and 02. High levels of antimicrobial resistance were found. Gram-positive strains had the highest resistance to tetracycline (46.1\%), enrofloxacin, cotrimazol and streptomycin $(42.3 \%$ each), while above $50 \%$ of Gram-negative were resistant to amoxicillin and tetracycline. Multidrug resistance has been observed in more than $50 \%$ of the major genera isolated. Considering the zoonotic potential of $E$. coli strains and its strong participation in antimicrobial resistance dissemination, the important role of the veterinarians in the prevention and control of animal UTIs and their contribution to public health must be emphasized.
\end{abstract}

INDEX TERMS: Urinary tract infection, dogs, cats, Escherichia coli, antibiotic resistance.

RESUMO.- As infecções bacterianas do trato urinário (ITUs) são causa comum de doença em cães, gatos e humanos. Embora bactérias Gram positivas como Staphylococcus spp., Streptococcus spp. e Enterococcus spp., possam ocasionar ITUs, as bactérias Gram negativas (Escherichia coli, Proteus spp., Klebsiella spp., Pseudomonas spp. e Enterobacter

\footnotetext{
${ }^{1}$ Recebido em 10 de julho de 2013.

Aceito para publicação em 19 de novembro de 2013.

${ }^{2}$ Laboratório de Biologia Molecular e Celular, Universidade Paulista (Unip), Av. José Maria Whitaker 290, 3o andar, São Paulo, SP 04057-000, Brasil.*Autor para correspondência: vaniamc@uol.com.br

${ }^{3}$ Instituto Adolfo Lutz, Centro de Bacteriologia, Av. Dr Arnaldo 351/355, 9o andar, São Paulo, SP 01246-902.

${ }^{4}$ Lab\&Vet Diagnóstico e Consultoria Veterinária Ltda, Av. Escola Politécnica 4445, São Paulo, SP 05350-000.
}

spp.) respondem por $75 \%$ dos casos. Este estudo teve como objetivo determinar a frequência de diferentes gêneros de bactérias em ITUs em cães e gatos, bem como a sua sensibilidade aos antimicrobianos utilizados na rotina clínica. Portanto, amostras de urina de 100 cães e gatos com sinais de ITU foram coletadas assepticamente, sofrendo avaliação microbiológica por meio de métodos qualitativos e quantitativos, além de urinálise. Todos os isolados foram submetidos a testes de sensibilidade aos antimicrobianos. ITU foi confirmada em $74 \%$ dos animais, não havendo predominância quanto ao sexo. No que diz respeito à idade, $85 \%$ dos cães e $87 \%$ dos gatos tinham idades superiores a seis anos. Noventa e cinco cepas bacterianas foram isoladas, com maior frequência de Escherichia coli (55\% do total) dos sorogrupos 06 e 02. Constatou-se níveis elevados 
de resistência a antimicrobianos nas cepas isoladas. Para as cepas Gram positivas, tetraciclina $(46,1 \%)$, enrofloxacina, cotrimazol e estreptomicina ( $42,3 \%$ cada) foram as drogas com os maiores índices de resistência. Para as Gram negativas, amoxacilina e tetraciclina apresentaram percentuais acima de 50\%. Multiresistência foi verificada em mais de $50 \%$ dos principais gêneros isolados. Considerando-se que as cepas de E. coli apresentam potencial zoonótico e forte participação na disseminação de resistência aos antimicrobianos, ressalta-se a importância do papel do médico veterinário na prevenção e controle das ITUs animais e sua contribuição para a saúde pública.

TERMOS DE INDEXAÇÃO: Infecção do trato urinário, caninos, felinos, Escherichia coli, resistência a antibióticos.

\section{INTRODUÇÃO}

As infecções do trato urinário (ITU) são uma das causas mais frequentes de doença nos cães, tendo menor ocorrência nos gatos (Barsanti 2006). Estimativas indicam que número elevado de cães irão desenvolver esta afecção em alguma fase da vida, sendo esta majoritariamente de origem bacteriana (Blanco \& Bartges 2001, Johnson et al. 2003, Bartges 2004, Barsanti 2006, Thompson et al. 2011).

o trato urinário é usualmente um ambiente estéril, excetuando-se a uretra distal que apresenta, naturalmente, micro-organismos residentes. Portanto, a definição de ITU está relacionada à colonização microbiana do epitélio estratificado dos variados nichos do trato urinário como, mucosa uretral, bexiga, ureteres, pelve renal, túbulos contorcidos e dutos coletores dos rins (Barsanti 2006). A multiplicação bacteriana em locais do trato urogenital geralmente desprovidos de microbiota se deve, principalmente, à ascensão de bactérias presentes na porção distal da uretra, muitas vezes originárias da microbiota intestinal (Low et al. 1988, Blanco \& Bartges 2001, Johnson et al. 2003). A criação de um ambiente favorável para tal fenômeno se dá graças às alterações dos mecanismos de defesa do hospedeiro e à presença de fatores de virulência bacterianos que as tornam mais aptas ao parasitismo (Johnson 1991, Johnson et al. 2003).

Tanto bactérias Gram positivas (Staphylococcus spp., Streptococcus spp. e Enterococcus spp.) como Gram negativas podem ocasionar ITUs. Em 75\% dos casos, entretanto, as infecções tem como etiologia as Gram negativas (Escherichia coli, Proteus spp., Klebsiella spp., Pseudomonas spp. e Enterobacter spp.), (Seguin et al. 2003, Barsanti 2006), sendo a Escherichia coli, isoladamente, o principal agente etiológico desta infecção nos animais e no homem (Low et al. 1988, Blanco \& Bartges 2001, Ling et al. 2001, Johnson et al. 2003, Seguin et al. 2003, Bartges 2004). Existem evidências de que pode haver a transmissão cruzada desta bactéria entre os cães e o homem (Cherifi et al. 1991, Johnson et al. 2001, Johnson \& Clabots 2006), situação epidemiológica complexa, uma vez que a $E$. coli é um dos principais partícipes da disseminação de resistência aos antimicrobianos (Pitout 2012).

Dados nacionais e internacionais dão conta que na última década, o controle e tratamento das ITU, sobretudo aquelas de origem humana, tem se complicado devido à emergência de resistência por parte das bactérias (Andrade et al. 2006, Pitout 2012). Fenômeno semelhante tem sido reportado por autores estrangeiros em isolados animais, inclusive, tendo sido demonstrado uma evolução no perfil de multirresistência em cepas de origem animal ao longo dos anos, sendo os animais de companhia assinalados como reservatórios de bactérias resistentes (Guardabassi et al. 2004, Ball et al. 2008, Gibson et al. 2008).

Em nosso meio, no entanto, pouca informação científica está disponível acerca de ITU em cães e gatos e, em especial, a respeito de resistência aos antibióticos. 0 presente trabalho teve por objetivo verificar a prevalência de diferentes gênero bacterianos em infecções do trato urinário de cães e gatos, assim como a sensibilidade dos isolados aos antimicrobianos utilizados na rotina clínica.

\section{MATERIAL E MÉTODOS}

Animais. Foram colhidas, através de cateterização, cistocentese ou micção espontânea, amostras de urina de 100 animais (86 cães e 14 gatos) com suspeita clínica de infecção nas vias urinárias, provenientes de clínicas de diferentes regiões da cidade de São Paulo. Os animais foram amostrados a medida que ocorria a suspeita desta afecção. A confirmação da suspeita baseou-se na avaliação bacteriana quantitativa da urina, associada aos resultados de urinálise. As amostras foram acondicionadas em recipientes estéreis, transportadas sob refrigeração, sendo processadas no prazo máximo de 6 horas (Blanco \& Bartges 2001, Bartges 2004).

Urinálise. A urinálise empregou as técnicas laboratoriais rotineiras, com vistas à detecção de alterações no sistema urinário (Meyer et al. 1995, Bartges 2004). Foram utilizadas Tiras de Urina Combur 10 (Roche ${ }^{\mathrm{TM}}$ ) para a avaliação de $\mathrm{pH}$, proteínas $(\mathrm{mg} / \mathrm{dL})$, glicose $(\mathrm{mg} / \mathrm{dL})$, corpos cetônicos $(\mathrm{mg} / \mathrm{dL})$, bilirrubina $(\mathrm{mg} / \mathrm{dL})$, hemoglobina hemolisada, urubilinogênio $(\mathrm{mg} / \mathrm{dL})$, eritrócito não hemolisado (ERI $/ \mu \mathrm{L}$ ), leucócitos (Leuco $/ \mu \mathrm{L}$ ), densidade e nitrito. Além disso, foi realizada a avaliação do sedimento urinário para a pesquisa e quantificação de eritrócitos, leucócitos, células epiteliais de descamação, cilindros, cristais e bactérias.

Cultura e identificação bacteriana. Foram utilizados para determinação do agente etiológico métodos qualitativos e quantitativos. A avaliação qualitativa teve o objetivo de isolar e identificar bactérias presentes na urina. Esta foi realizada a partir da semeadura da urina em ágar sangue (Base para ágar sangue-Difco ${ }^{\mathrm{TM}}$ ) e ágar MacConkey (Difco ${ }^{\mathrm{TM}}$ ) (Bartges 2004). A identificação das amostras isoladas foi feita de acordo com as técnicas rotineiras de identificação bioquímica (Koneman 1997), incluindo os kits de identificação bioquímica EPM, MiLi, Citrato (Probac ${ }^{\mathrm{TM}}$ ), kit NF (Probac ${ }^{\mathrm{TM}}$ ), kit para a identificação de Enterococcus spp. (Probac ${ }^{\mathrm{TM}}$ ) e Staphy test (Probac ${ }^{\mathrm{TM}}$ ). Em placas que continham mais de três gêneros bacterianos, estes foram considerados contaminantes.

A avaliação quantitativa, considerada padrão de referência para ITUs (Bartges 2004, Lulich \& Osborne 2004), determinou o número unidades formadoras de colônias (UFC) por mililitro de urina. A quantificação bacteriana foi feita em duas placas de ágar Tryptic Soy (Difco ${ }^{\mathrm{TM}}$ ), através da semeadura e espalhamento com alça de Drigalski de $10 \mu \mathrm{L}$ e $100 \mu \mathrm{L}$ de urina, respectivamente. A interpretação dos resultados obtidos nas avaliações quantitativas foi realizada conforme o preconizado por Polzin (1994) e serviu de referência para o diagnóstico de ITU desta pesquisa.

Dos animais em que se obteve a identificação de Escherichia coli foram isoladas 3 colônias para a sorotipagem. 
Teste de sensibilidade aos antimicrobianos. Foram realizados testes de sensibilidade às drogas antimicrobianas com 94 bactérias isoladas, através do teste de disco difusão, segundo os padrões determinados internacionalmente tendo como base a técnica de Kirby-Bauer (CLSI 2008a, 2008b). Foram utilizados antibióticos empregados para o tratamento de cães com ITU: Penicilinas (penicilina G e amoxicilina), Cefalosporinas (cefalexina, cefotaxima, ceftiofur), Fluorquinolonas (ciprofloxacina e enrofloxacina), Aminoglicosídeos (estreptomicina e gentamicina), cloranfenicol, tetraciclina, nitrofurantoína e sulfadiazina+trimetoprim (cotrimazol). Foram consideradas multirresistentes as cepas que demonstraram resistência a três ou mais classes de antimicrobianos (Schwartz et al. 2010)

Sorotipagem das cepas de Escherichia coli. Foi realizada a sorotipagem de 129 cepas de E. coli (provenientes de 43 animais). Estas foram sorogrupadas através da utilização de anti-soros para os antígenos 0 (anti-soros 01 a 0181), de acordo com as técnicas sorológicas internacionalmente padronizadas (Ewing 1986).

\section{RESULTADOS}

Dos 100 animais amostrados 86 eram cães, sendo que $25 \%$ não apresentaram raça definida, distribuindo-se o restante em 23 diferentes raças, com predomínio de Poodle (9\%), Pastor alemão e Schnauzer (8\% cada), Cocker Spaniel e Dachshund (7\% cada). Com relação aos 14 gatos, $43 \%$ corresponderam a animais SRD e o mesmo percentual a Siameses.

A avaliação quantitativa microbiológica permitiu a confirmação de ITU em 74 indivíduos, sendo que outros cinco foram considerados suspeitos devido à contagem UFC $/ \mathrm{mL}$ e à alta contagem de leucócitos na urinálise (Quadro 1). Entre os 74 animais, confirmou-se ITU em 10/14 dos gatos (71\%) e 64/86 dos cães amostrados (74\%).

Nos outros 21 animais (excluindo-se os 74 indivíduos com ITU confirmada e os cinco suspeitos), verificou-se em 9 deles resultados da urinálise compatíveis com suspeita de ITU, entretanto, crescimento de variados contaminantes (Quadro 1). Entre os 12 animais em que não ocorreu crescimento bacteriano, seis (quatro cães e dois gatos) apresentaram alterações na urinálise compatíveis com ITU; nos outros seis cães os resultados da urinálise foram inconclusivos. Das 12 amostras em que não ocorreu cresci- mento bacteriano, apenas duas tiveram a colheita realizada por micção espontânea (17\%). Já, entre as nove em que ocorreu o crescimento de contaminantes, sete tiveram este procedimento de colheita (78\%).

Como nem todos os proprietários forneceram a idade dos animais, considerando-se a idade de 67 dos 74 animais com ITU confirmada, $83 \%$ e $87 \%$ dos cães e gatos, respectivamente, tinham idades superiores a seis anos. A média etária dos cães foi de nove anos (variando de 1 a 20) e dos gatos de oito (variando de 1 a 16).

Dos 74 animais, 39 eram machos (32 cães e sete gatos) e 35 eram fêmeas ( 32 cadelas e 3 gatas). Considerando-se os parâmetros medidos pela urinálise, $100 \%$ dos 74 animais com ITU demonstraram acima de dez leucócitos por campo (100\% destes associados à presença de hemácias), sendo que em 31/74 (42\%) dos animais verificaram-se incontáveis células (piúria).

Proteinúria esteve presente em $70 \%$ dos indivíduos. Com relação à bactérias, em $72 \%$ a presença destas no sedimento urinário alcançou pelo menos duas cruzes. Nitritos, por outro lado, foi verificado em apenas 19\% dos animais com ITU.

Foram isoladas 95 amostras bacterianas (89/74 animais com ITU confirmada e 6/5 animais suspeitos). Em $64 / 79(81,0 \%)$ amostras de urina estas estavam em culturas puras e em 15/79 (19,0\%) em culturas mistas. Dentre as amostras isoladas em culturas mistas, em cinco animais foram obtidas duas cepas bacterianas da mesma espécie, porém, com diferenças na sensibilidade aos antimicrobianos. Nas outras 10, foram isolados diferentes gêneros, estando em $100 \%$ das vezes $E$. coli envolvida.

Considerando-se apenas os animais com ITU confirmada, Escherichia coli foi isolada em 41/74 amostras de urina (55\%), Staphylococcus spp. em 15/74 (20\%) - (6/15 Staphylococcus spp. coagulase + ), Proteus mirabilis em 12/74 (16\%), Streptococcus spp. em três (4\%), Enterococcus spp. em duas (3\%), outras enterobactérias (Citrobacter spp., Serratia liquefaciens, Enterobacter aerogenes e Klebsiella pneumoniae) em oito (11\%) das amostras de urina, Gram negativos "não enterobactéria" (Pseudomonas aeruginosa, Burkolderia cepacia, Chryseobacterium meningosepticum) em 3 (4\%) amostras urinárias (Quadro 2).

\begin{tabular}{|c|c|c|c|}
\hline $\begin{array}{l}\text { Número de } \\
\text { animais }\end{array}$ & $\begin{array}{l}\text { Número de animais/ } \\
\text { Resultado da urinálise }\end{array}$ & $\begin{array}{l}\text { Número de animais } \\
\text { por tipo de colheita }\end{array}$ & $\begin{array}{l}\text { Contagem } \mathrm{UFC} / \mathrm{mL}^{\mathrm{b}} / \\
\text { Diagnóstico final }\end{array}$ \\
\hline $\begin{array}{l}10 \text { gatos } \\
64 \text { cães }\end{array}$ & 74 /Alterações compatíveis com ITU & $\begin{array}{c}28 \mathrm{Ci} \\
18 \mathrm{Ca} \\
24 \mathrm{ME} \\
4 \mathrm{NR}\end{array}$ & Significante/ ITU \\
\hline $\begin{array}{l}2 \text { gato } \\
3 \text { cães }\end{array}$ & 5 /Alterações compatíveis com ITU & $\begin{array}{l}2 \mathrm{Ci} \\
1 \mathrm{Ca} \\
2 \mathrm{ME}\end{array}$ & Suspeito/ Suspeita de ITU \\
\hline 9 cães & 9 /Alterações compatíveis com ITU & $\begin{array}{c}1 \mathrm{Ci} \\
7 \mathrm{ME} \\
1 \mathrm{NR}\end{array}$ & Contaminantes/ITU não confirmada \\
\hline $\begin{array}{l}10 \text { cães } \\
2 \text { gatos }\end{array}$ & $\begin{array}{c}6 \text { /Alterações compatíveis com ITU } \\
6 \text { /Ausência de alterações }\end{array}$ & $\begin{array}{ll}7 \mathrm{Ci} & \mathrm{Sem} \\
2 \mathrm{Ca} & \\
2 \mathrm{ME} & \\
1 \mathrm{NR} & \end{array}$ & crescimento bacteriano/ ITU não confirmada \\
\hline
\end{tabular}

Pesq. Vet. Bras. 34(1):62-70, janeiro 2014 
Nos animais considerados suspeitos, Escherichia coli e Staphylococcus spp. coagulase negativo foram isolados em dois animais cada, sendo que um isolado de Staphylococcus sp. estava associado à Streptococcus sp. Além disso, isolou-se Bacillus sp. de um animal.

Para um mesmo indivíduo, a sorogrupagem das três cepas de E. coli isoladas, teve o mesmo resultado. Assim sendo, na tabela 3 encontra-se o resultado referente a 43 cepas de E coli (41 cepas de ITU confirmada e 2 cepas de animais com suspeita de ITU).

Das 43 cepas de E. coli, foi possível determinar o sorogrupo em $27(62,8 \%)$ cepas. Três cepas $(7,0 \%)$ apresentaram O rugoso (OR) e em $13(30,2 \%)$ amostras não foi possível tipificar o antígeno 0 (ONT). O sorogrupo mais prevalente foi o $06(20,9 \%)$, seguido pelo 02 (12,2\%) (Quadro 3).

Dos 95 isolados bacterianos, o teste de sensibilidade às drogas foi realizado com 94 deles (uma cepa foi perdida nos procedimentos laboratoriais). Para as cepas Gram positivas, os maiores índices de resistência estiveram relacionados à tetraciclina $(46,1 \%)$, enrofloxacina, cotrimazol e estreptomicina (42,3\% cada); outro aminoglicosídeo, a gentamicina, apresentou percentuais mais baixos de cepas resistentes $(19,2 \%)$. Percentuais semelhantes de resistência foram observados com relação às penicilinas e à cefotaxima (23,1\% cada). Para cloranfenicol e outras cefalosporinas, os percentuais de cepas resistentes foram 15,4\% e 11,5\%,

\section{Quadro 2. Número e percentual de bactérias isoladas de} cães e gatos com ITU

\begin{tabular}{lccc}
\hline & \multicolumn{3}{c}{ Animais } \\
\cline { 2 - 4 } Micro-organismo & Felinos & Caninos & Total \\
& $\mathrm{N}=10$ & $\mathrm{~N}=64$ & $\mathrm{~N}=74$ \\
& $\mathrm{no.} \%$ & $\mathrm{no.} \%$ & $\mathrm{no.} \%$ \\
\hline Escherichia coli & $6(60 \%)$ & $26(40,6 \%)$ & $32(43,2 \%)$ \\
Associação com & $1(10 \%)$ & $8(12,5 \%)$ & $9(12,2 \%)$ \\
Escherichia coli & & & $12(16,2 \%)$ \\
Proteus mirabilis & $1(10 \%)$ & $11(17,2 \%)$ & $8(10,8 \%)$ \\
Outras enterobactérias & - & $8(12,5 \%)$ & $3(4,1 \%)$ \\
Outras Gram $-/$ & $1(10 \%)$ & $2(3,1 \%)$ & $15(20,3 \%)$ \\
não enterobactérias & & & $3(4,1 \%)$ \\
Staphylococcus spp. & - & $15(23,4 \%)$ & $2(2,7 \%)$ \\
Streptococcus spp. & $1(10 \%)$ & $2(3,1 \%)$ & \\
Enterococcus spp. & - & $2(3,1 \%)$ &
\end{tabular}

Quadro 3. Número e percentuais dos sorogrupos de Escherichia coli isolados de cães e gatos com ITU

\begin{tabular}{lccc}
\hline & \multicolumn{3}{c}{ Animais } \\
\cline { 2 - 4 } Sorotipo & $\begin{array}{c}\text { Felinos } \\
\text { no./\% }\end{array}$ & $\begin{array}{c}\text { Caninos } \\
\text { no./\% }\end{array}$ & $\begin{array}{c}\text { Total } \\
\text { no. } / \%\end{array}$ \\
\hline 02 & $1(14,3 \%)$ & $4(11,8 \%)$ & $5(12,2 \%)$ \\
04 & - & $1(2,9 \%)$ & $1(2,4 \%)$ \\
06 & $2(28,6 \%)$ & $7(19,4 \%)$ & $9(20,9 \%)$ \\
011 & - & $1(2,9 \%)$ & $1(2,4 \%)$ \\
015 & $1(14,3 \%)$ & - & $1(2,4 \%)$ \\
018 & $1(14,3 \%)$ & - & $1(2,4 \%)$ \\
020 & - & $1(2,9 \%)$ & $1(2,4 \%)$ \\
021 & $1(14,3 \%)$ & $1(2,9 \%)$ & $2(4,9 \%)$ \\
023 & - & $1(2,9 \%)$ & $1(2,4 \%)$ \\
025 & - & $2(5,9 \%)$ & $2(4,9 \%)$ \\
083 & - & $2(5,9 \%)$ & $2(4,9 \%)$ \\
0153 & - & $1(2,9 \%)$ & $1(2,4 \%)$ \\
ONT ou OR & $1(14,3 \%)$ & $15(41,7 \%)$ & $16(37,2 \%)$ \\
Total & 7 & 36 & 43
\end{tabular}

respectivamente. 0 menor número de cepas resistentes foi verificado quanto à nitrofurantoína (9,5\%) (Quadro 4).

Sem levar em consideração a benzil-penicilina, antimicrobiano ao qual bactérias Gram negativas podem apresentar resistência intrínseca, a aminopenicilina, amoxicilina e a tetraciclina foram os antimicrobianos com maior percentual de cepas Gram negativas resistentes (acima de 50\%). Estreptomicina e cotrimazol apesentaram índices de cepas resistentes próximas à 36\%, sendo o percentual de resistência à gentamicina menor, 10,3\%. Entre as cefalosporinas, apenas a cefalexina exibiu número elevado de cepas resistentes $(17,6 \%$, contra $2,9 \%$ de resistência à cefotaxima e ceftiofur). Com relação às fluorquinolonas e cloranfenicol, aproximadamente $15 \%$ das cepas se mostraram resistentes. As cepas Gram negativas deste estudo apresentaram 22,1\% de resistência à nitrofurantoína (Quadro 5).

Os índices de multirresistência dos diferentes patógenos foi elevado, uma vez que as espécies isoladas com maior frequência apresentaram ao redor de 50\% de multirresistência (Quadro 6).

\section{DISCUSSÃO}

Houve a confirmação de ITU em um maior número de cães do que de gatos considerando-se números absolutos, entretanto, em termos percentuais, os números se assemelharam (71\% dos gatos contra 74\% dos cães estudados). Dados da literatura imputam aos cães um maior acometimento por infecções do trato urinário do que aos gatos (Bartges 2004). Este tipo de avaliação não foi possível ser realizada neste estudo, uma vez que a colheita de dados privilegiou animais com suspeita de ITU e não uma amostragem da população estimada de cães e gatos de diferentes regiões da cidade de São Paulo. A discrepância entre o número de solicitações de exames urinários nas duas espécies, contudo, pode estar relacionada entre outros fatores, à maior população de cães em nosso meio quando comparada à população de gatos (Canatto et al. 2012).

A colheita realizada através da micção espontânea mostrou-se menos adequada do que os outros procedimentos, uma vez que um maior número de amostras contaminadas foi verificada após a utilização deste método. Devido a isso, vários autores recomendam a utilização preferencial de cistocentese (Bartges 2004, Lulich \& Osborne 2004). Por outro lado, quando há impossibilidade de realização de cistocentese ou cateterismo, este método poderia ser empregado desde que ocorra a realização de uma antissepsia adequada, uma vez que 17\% (2/12) de amostras de animais sem indícios laboratoriais de ITU e negativos na avaliação microbiológica, tiveram esse tipo de colheita.

0 número de cães machos e fêmeas acometidos foi idêntico, não se observando ocorrência maior em nenhum dos sexos. 0 mesmo não ocorreu com os felinos que tiveram um maior número de machos acometidos. Outros autores relataram maiores frequências de ITU em fêmeas (Ling et al. 2001, Cohn et al. 2003), entretanto, como o já referido anteriormente, a amostragem intencional da presente pesquisa impossibilita a comparação com estes resultados.

Com relação aos parâmetros medidos pela urinálise, $100 \%$ dos animais com ITU mostraram acima de dez leu- 


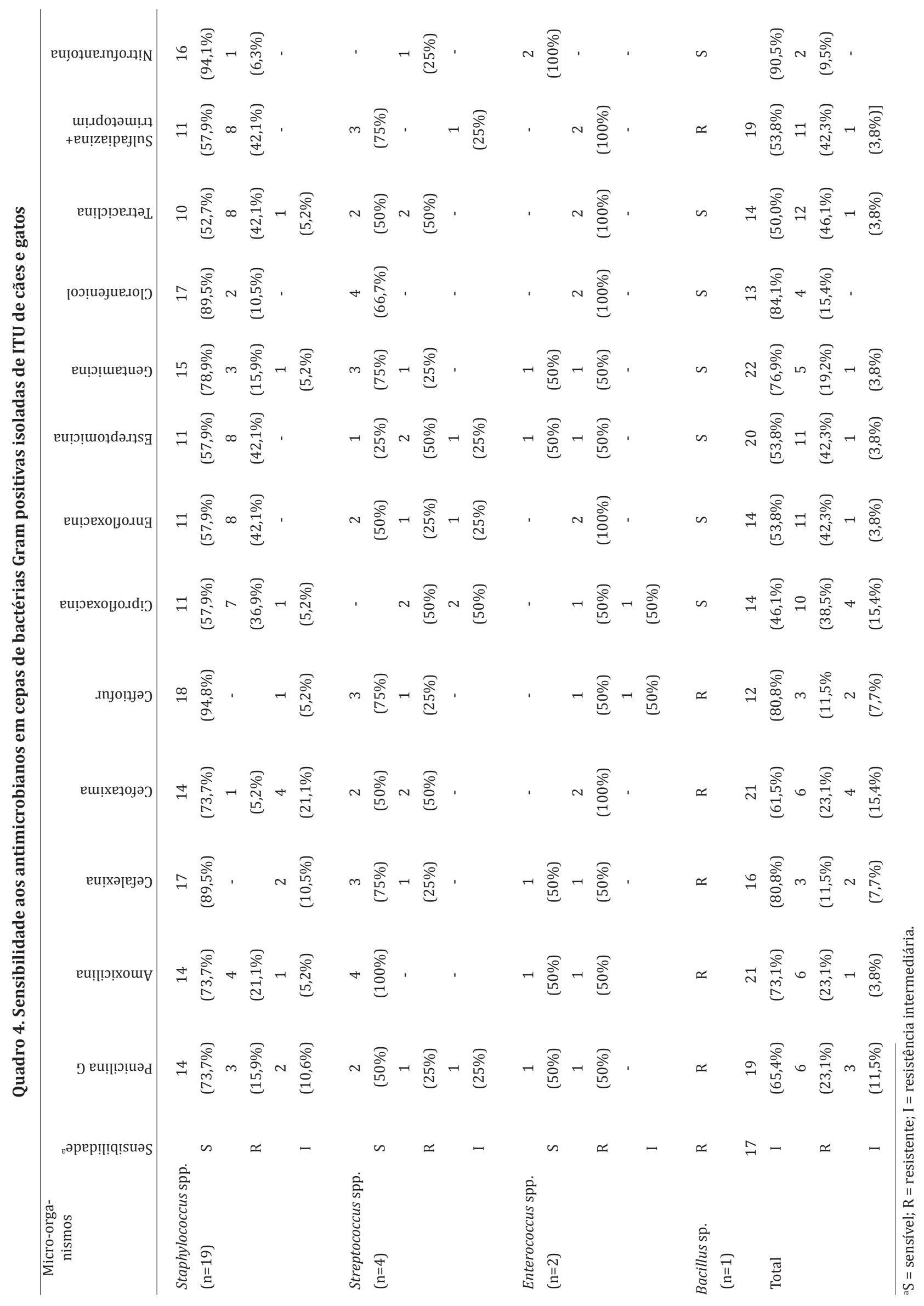




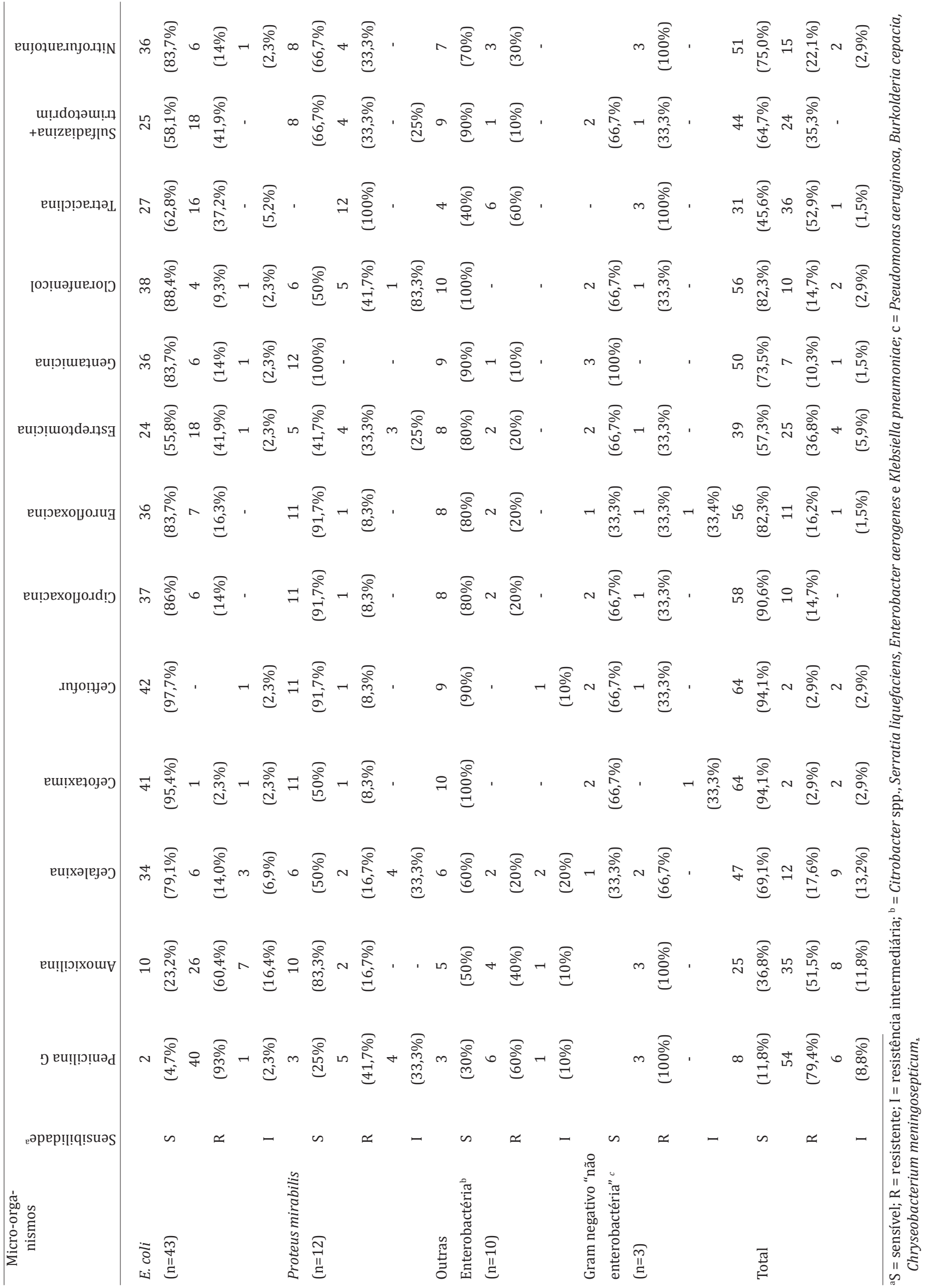


Quadro 6. Número e percentual de cepas multirresistentes isoladas de ITU de cães e gatos

\begin{tabular}{ccc}
\hline Número de cepas & Bactéria & $\begin{array}{c}\text { Multiresitência } \\
\text { No. de cepas / \% }\end{array}$ \\
\hline 43 & Escherichia coli & $20(46 \%)$ \\
12 & Proteus mirabilis & $6(50 \%)$ \\
10 & Outras enterobactérias & $2(20 \%)$ \\
3 & Gram -/não enterobactéria & $3(100 \%)$ \\
19 & Staphylococcus spp. & $8(42 \%)$ \\
4 & Streptococcus spp. & $2(50 \%)$ \\
2 & Enterococcus spp. & $2(100 \%)$
\end{tabular}

cócitos por campo, sendo que em $41 \%$ detectou-se piúria. Segundo Meyer et al. (1995) e Bartges (2004), 0-3 leucócitos poderiam ser encontrados a partir da colheita por cistocentese e 5-10 por cateterização ou micção espontânea. A urina normal apresenta baixo número de eritrócitos (0-3 por campo) (Meyer et al. 1995), por isso, o número elevado, associada à contagem alta de leucócitos como o verificado no presente estudo, confirmam a ocorrência de inflamação.

Proteinúria foi verificada em $70 \%$ dos animais apresentando ITU. A proteinúria pós-renal ocorre em processo inflamatório do trato urinário inferior e é acompanhada usualmente de hematúria e/ou piúria (Meyer et al. 1995, Bartges 2004), fato verificado nos animais amostrados.

Nos indivíduos com ITU a avaliação microbiológica revelou contagens bacterianas acima de 100.000 organismos/mL. Em 72\% destes, a presença de bactérias no sedimento urinário alcançou pelo menos duas cruzes. Este último dado é significativo de infecção, uma vez que na maioria das vezes, bactérias só são visualizadas no sedimento urinário quando em grandes números (p.ex.: bastonetes e cocos são detectados, respectivamente, acima de $10.000 \mathrm{e}$ 100.000 bact/mL) (Blanco \& Bartges 2001).

Nitritos, embora seja um parâmetro altamente sugestivo de infecção urinária no homem, em cães e gatos é pouco significativo, uma vez que o ácido ascórbico na urina destes animais mascara a presença de nitritos (Blanco \& Bartges 2001). Os resultados apresentados corroboram essa informação, visto que apenas 19\% dos animais com ITU demonstraram nitritos na urina.

Das 75 amostras clínicas de urina em que foi confirmada ITU, verificou-se em 61 delas o isolamento de culturas puras (81\%), dados compatíveis com os obtidos por outros autores que referem que mais de $70 \%$ das UTIs são causadas por um único agente, sendo pequena a proporção de infecções mistas (Ling et al. 2001, Drazenovich et al. 2004).

Os gêneros bacterianos isolados neste estudo foram semelhantes aos encontrados por outros pesquisadores e citadas na literatura relacionada a infecções do trato urinário (Bartges 2004, Barsanti 2006).

A bactéria Escherichia coli foi a mais prevalente entre os isolados, estando presente em 53\% (34/64) das amostras de urina de cães e $70 \%(7 / 10)$ das amostras de gato com ITU. Estes valores são próximos, entretanto, ligeiramente superiores aos encontrados por outros autores (Seguin et al. 2003, Drazenovich et al. 2004) e indicam ser também em nosso meio, este o patógeno mais comumente envolvido nas ITUs de cães e gatos.
É interessante ressaltar o possível caráter clonal da infecção por este patógeno, uma vez que as três cepas de $E$. coli isoladas de um mesmo indivíduo foram classificadas no mesmo sorogrupo. A origem clonal da infecção por E. coli é imputada à atributos de virulência bacterianos específicos que facilitariam a instalação e multiplicação de determinado clone em local supostamente inóspito como o sistema urinário (Thompson et al. 2011). Os sorogrupos representados pelas cepas do presente estudo estão entre os mais frequentemente relacionados às infecções urogenitais de cães, gatos e humanos como, 02, 04, 06, 011, 018 e 025 (Low et al. 1988, Yuri et al. 1998, Johnson 1991, Johnson 2001). Sendo que os sorogrupos 02, 04, 06 e 025 representaram ao redor de $40 \%$ dos isolados, e estão fortemente relacionados a infecções zoonóticas (Cherifi et al. 1991, Johnson et al. 2001, 2006, 2008, Bélanger et al. 2011).

O segundo grupo de bactérias mais prevalentes foi o de cocos Gram positivo (Staphylococcus spp., Streptococcus spp. e Enterococcus spp.) constituindo 34\% dos isolados, dados estes também compatíveis com os relatados por outros autores (Bartges 2004, Barsanti 2006,).

Proteus mirabilis foi isolado em $16 \%$ dos casos de ITU, constituindo-se o terceiro gênero mais prevalente. Estes achados corroboram os de Cohn et al. (2003) cujos percentuais foram relacionados às cadelas não castradas.

No tocante à utilização de antimicrobianos no tratamento das ITUs, os resultados obtidos no presente trabalho, confirmam dados expostos por outros autores que registraram elevada prevalência de resistência entre os isolados de ITU de animais, à semelhança do observado em isolados humanos (Prescott et al. 2002, Cohn et al. 2003, Nickel 2005, Andrade et al. 2006).

Consideradas drogas de primeira escolha para o tratamento de ITUs animais, sulfa+trimetoprim, amoxicilina, cefalexina (Barsanti 2006) e tetraciclina (Thompson et al. 2011), não foram efetivas in vitro para elevado número de isolados. No computo geral as bactérias Gram negativas apresentaram, respectivamente, 35,3\%, 63,2\%, 30,9\% e $54,4 \%$ de resistência a estas drogas, enquanto as Gram positivas tiveram $46,9 \%, 26,9 \%, 19,2 \%$ e $49,9 \%$. Para E. coli, patógeno que corresponde isoladamente ou em associação a mais de $50 \%$ das bactérias deste estudo, os maiores percentuais de resistência foram relacionados a amoxicilina $(76,8 \%)$, estreptomicina $(44,2 \%)$, sulfa+timetoprim $(41,9 \%)$ e tetraciclina $(37,2 \%)$. Já os Staphylococcus spp., segundo gênero em número de isolados, demonstraram os maiores percentuais de resistência à tetraciclina $(47,3 \%)$, sulfa+trimetoprim $(42,1 \%)$, estreptomicina $(42,1 \%)$ e enrofloxacina $(42,1 \%)$. Esses resultados provavelmente refletem a ampla utilização desses princípios ativos, já que estas são as drogas de maior utilização na prática clínica em nosso meio. Diversos estudos têm demonstrado que o emprego contínuo de determinadas drogas acaba por exercer uma pressão seletiva que resulta no aparecimento de resistência ao longo do tempo, o que torna os animais de companhia reservatórios de bactérias resistentes (Cooke et al. 2002, Prescott et al. 2002, Guardabassi et al. 2004).

Nesse contexto deve-se reservar atenção às fluorquinolonas, como por exemplo a enrofloxacina, de empre- 
go exclusivo em medicina veterinária. Estas são drogas amplamente utilizadas no tratamento de ITUs, já que são recomendadas para as ITUs complicadas ou recorrentes, causadas por bactérias Gram negativas resistentes às drogas de primeira escolha (Barsanti 2006). A emergência de resistência às fluorquinolonas tem sido documentada tanto em cepas animais quanto nas de origem humana (Cooke et al. 2002, Prescott et al. 2002, Cohn et al. 2003, Nickel 2005, Andrade et al. 2006). Conquanto tenha sido verificado menor percentual de resistência nas bactérias Gram negativas desta pesquisa, ressalta-se que E. coli, micro-organismo mais prevalente deste estudo, é considerada importante disseminadora de genes de resistência às fluorquinolonas e cefalosporinas (Pitout 2012).

Merece atenção especial, todavia, a multirresistência verificada em elevado percentual das cepas bacterianas desta pesquisa, fenômeno que dificulta a intervenção terapêutica nos animais acometidos, além de possibilitar que estes disseminem cepas resistentes para o ambiente e para a população humana (Guardabassi et al. 2004). No tocante a E. coli, discute-se o papel dos animais de companhia na emergência mundial de clone altamente virulento (O25:H4-ST131), que congrega concomitantemente resistência à várias drogas, como fluorquinolonas e cefalosporinas de terceira geração (Ewers et al. 2010).

Os resultados do presente estudo tanto reforçam a ideia de que a realização de testes de sensibilidade aos antimicrobianos são de fundamental importância, como reavivam a relevância do papel do médico veterinário na prevenção e controle das ITUs animais afim de minimizar a disseminação da resistência bacteriana e seu impacto nas Saúdes Animal e Pública.

Agradecimentos.- À FAPESP pela concessão de Auxílio à Pesquisa (processo 06/54343-2), ao CNPq por bolsa de Iniciação Científica (PIBIC) e ao LAB\&VET Diagnóstico e Consultoria Veterinária LTDA, pela colaboração na colheita das amostras clínicas.

\section{REFERÊNCIAS}

Andrade S.S., Sader H.S., Jones R.N., Pereira A.S., Pignatari A.C. \& Gales A.C. 2006. Increased resistance to first-line agents among bacterial pathogens isolated from urinary tract infections in Latin America: time for local guidelines? Mem. Inst. Oswaldo Cruz 101:741-8.

Ball K.R., Rubin J.E., Chirino-Trejo M. \& Dowling P.M. 2008. Antimicrobial resistance and prevalence of canine uropathogens at the Western College of Veterinary Medicine Veterinary Teaching Hospital, 2002-2007. Can. Vet. J. 49:985-90.

Barsanti J.A. 2006. Genitourinary infections, p.626-646. In: Greene C.E. (Ed.), Infectious Diseases of the Dog and Cat. $2^{\text {nd }}$ ed. W.B. Sauders, Philadelphia. 1387p.

Bartges J.W. 2004. Diagnosis of urinary tract infections. Vet. Clin. Small. Anim. 34:923-933.

Bélanger L., Garenaus A., Harel J., Boulianne M., Nadeau E. \& Dozois C.M. 2011. Escherichia coli from animal reservoirs as a potential source of human extraintestinal pathogenic E. coli. Immunol. Med. Microbiol. 62:1-10.

Blanco L.J. \& Bartges J.W. 2001. Understanding and eradicating bacterial urinary tract infections. Vet. Med. 96:777-789.

Canatto B.D., Silva E.A., Bernardi F., Mendes M.C.N.C., Paranhos N.T. \& Dias R.A. 2012. Caracterização demográfica das populações de cães e gatos supervisionados do município de São Paulo. Arq. Bras. Med. Vet. Zootec. 64:1515-1523.
Cherifi A., Contrepois M., Picard B., Goullet P., Orskov I., Orskov F. \& De Rycke J. 1991. Clonal relationships among Escherichia coli serogroup 06 isolates from human and animal infections. FEMS Microbiol. Lett.. 64:225-230.

CLSI 2008a. CLSI document M31-A3. Clinical and Laboratory Standards Institute, Wayne, PA.

CLSI 2008b. CLSI document M100-S18 e M100-15. Clinical and Laboratory Standards Institutem Wayne, PA.

Cohn L.A., Gary A.T., Fales W.H. \& Madsen R.W. 2003. Trends in fluorquinolones resistance of bacteria from canine urinary tracts. J. Vet. Diagn. Invest. 15:338-343.

Cooke C.L., Singer R.S., Jang S.S. \& Hirsh D.C. 2002. Enrofloxacin resistance in Escherichia coli isolated from dogs with urinary tract infections. J. Am. Vet. Med. Assoc. 220:190-192.

Drazenovich N., Ling G. \& Foley J. 2004. Molecular investigation of Escherichia coli strains associated with apparently persistent urinary tract infection in dogs. J. Vet. Intern. Med. 18:301-306.

Ewers C., Grobbel M., Stamm I., Kopp P., Diehl I., Semmler T., Fruth A., Beutlich J., Guerra B., Wieler L. \& Guenther S. 2010. Emergence of human pandemic 025:H4-ST131 CTX-M-15 extended-spectrum-beta-lactamase-producing E. coli isolated from dogs in Portugal. J. Antimicrob. Chem. 65:651-660.

Ewing W. \& Edwards P. 1986. Edwards and Ewing's identification of Enterobacteriaceae. $4^{\text {th }}$ ed. Elsevier Science Publishers, New York. 1262p.

Gibson J.S., Morton J.M., Cobbold R.N., Sidjabat H.E., Filippich L.J. \& Trott D.J. 2008. Multidrug-resistant $E$. coli and enterobacter extraintestinal infection in 37 dogs. J. Vet. Intern. Med. 22:844-50.

Guardabassi L., Schwarz S. \& Lloyd D.H. 2004. Pet animals as reservoirs of antimicrobial-resistant bacteria. J. Antimicrob. Chem. 54:321-332.

Johnson J.R. \& Clabots C. 2006. Sharing of virulent Escherichia coli clones among household members of a woman with acute cystitis. Clin. Infect. Dis. 43:101-8.

Johnson J.R. 1991. Virulence factors in Escherichia coli urinary tract infections. Clin. Microbiol. 4:80-128.

Johnson J.R., Delavari P., Stell A.L., Whittam T.S., Carlino U. \& Russo T.A. 2001. Molecular comparison of extraintestinal Escherichia coli isolates of the same electrophoretic lineages from humans and domestic animals. J. Infect. Dis. 183:154-159.

Johnson J.R., Johnston B., Clabots C.R., Kuskowski M.A., Roberts E. \& Debroy C. 2008. Virulence genotypes and phylogenetic background of Escherichia coli serogroup 06 isolates from humans, dogs, and cats. J. Clin. Microbiol. 46:417-422.

Johnson J.R., Kaster N., Kuskowski M.A. \& Ling G.V. 2003. Identification of urovirulence traits in Escherichia coli by comparison of urinary and rectal E. coli isolates from dogs with urinary tract infection. J. Clin. Microbiol. 41:337-345.

Koneman E.W., Allen S.D., Janda W.M., Schreckenberger P.C. \& Winn Jr W.C. 1997. Color atlas and textbook of diagnostic microbiology. $5^{\text {th }}$ ed. Lippincott, Philadelphia. 1395p.

Ling G.V., Norris C.R., Franti C.E., Eisele P.H., Johnson D.L., Ruby A.L. \& Jang S.S. 2001. Interrelations of organism prevalence, specimen collection method, and host age, sex, and breed among 8,354 canine urinary tract infections (1969-1995). J. Vet. Intern. Med. 15:341-347.

Low D.A., Braaten B.A., Ling G.V., Johnson D.L. \& Ruby A.L. 1988. Isolation and comparison of Escherichia coli strains from canine and human patients with urinary tract infections. Infect. Immun. 56:2601-2609.

Lulich J.P. \& Osborne C.A. 2004. Urine culture as a test for cure: why, when, and how? Vet. Clin. Small Anim. 34:1027-1041.

Meyer D.J., Coles E.H. \& Rich L.J. 1995. Medicina de Laboratório Veterinária: diagnóstico e interpretação. Roca, São Paulo. 308p.

Nickel J.C. 2005. Management of urinary tract infections: historical perspective and current strategies: part 2- modern management. J. Urol. 173:27-32.

Pitout, J.D.D. 2012. Extraintestinal pathogenic Escherichia coli: a combination of virulence with antibiotic resistance. Front. Microbiol. 3:1-7. 
Polzin D.J. 1994. Management of recurrent bacterial urinary tract infections. Cycle Symp. 16:1565-1570.

Prescott J.F., Hanna W.J.B., Reid-Smith R. \& Drost K. 2002. Antimicrobial drug use and resistance in dogs. Can. Vet. J. 43:107-116.

Sampaio I.B.M. 1998. Estatística Aplicada à Experimentação Animal. UFMG, Belo Horizonte. 221p.

Schwarz S., Silley P., Simjee S., Woodford N., Van Duijkeren E., Hohnson A.P. \& Gaastra W. 2010. Editorial: assessing the antimicrobial susceptibility of bacteria obtained from animals. J. Antimicrob. Chemother. 65:601-604.
Seguin M.A., Vaden S.L., Altier C., Stone E. \& Levine J.F. 2003. Persistent urinary tract infections and reinfections in 100 dogs (1989-1999). J. Intern. Med. 17:622-631.

Thomson M.F., Lister A.L., Platell J.L. \& Trott D.J. 2011. Canine bacterial urinary tract infection: New developments in old pathogens. Vet. J. 190:2227.

Yuri K., Nakata K., Katae H., Tsukamoto T. \& Hasegawa A. 1998. Serotypes and virulence factors of Escherichia coli strains isolated from dogs and cats. J. Vet. Med. Sci. 61:37-40. 